\title{
Engaging with a healthy tourism "offer": strategies to improve place perceptions
}

\author{
Abstract \\ Purpose - The purpose of this paper is to explore how engagement with a healthy \\ tourism "offer"could improve place perceptions through the development of \\ collaborative strategies to promote a wellbeing destination.
}

Design/methodologylapproach - This paper takes a constructivist grounded theory approach drawing on semi-structured interviews conducted with local members of council from public health and tourism teams, in a seaside town in the South of England.

Findings - Study findings indicate that the historical roots of the town's creation have a bearing on current planning challenges and strategies. Findings confirm that collaborative strategies to engagewith a healthy tourism "offer" will improve place perceptions and promote a wellbeing destination.

Implications The paper concludes that strategies to engage with a healthy tourism offer include interventions to curb alcohol consumption, regenerate areas, and promote eudaimonic wellbeing -which could ultimately improve place perceptions.

Originality/value - This paper proposes that the development of a strategic alliances bridged through the construct of wellbeing could improve place perceptions and promote a wellbeing destination.

Keywords Public health, tourism, wellbeing, grounded theory, place, south of England

Paper type Research paper

\section{Introduction}

Researchers posit that there is an increasing focus on promoting health and wellbeing which is reflected in both tourism and public health government planning agendas (Daniel et al.2012; McCabe et al. 2010; Fayers and Machin 2007; Skevington et al. 2004). It is further offered that tourism and public health planning and practice are currently moving towards a new paradigm that considers overall societal health rooted in the wellbeing of individuals and communities. (Hair et al. 2010; Local Government Improvement and Development 2010).

These trends in thinking about tourism and public health offer opportunities for synergies in local development and planning. Within this context, there is an opportunity to develop a community culture that supports health creation and also presents a rebranding opportunity within the destination management approach. The tourism and travel industry are argued to play an important role in enhancing societal wellbeing and improving quality of life and ultimately creating healthier communities (Wise and Perić 2016; Munthe 2008). The role of tourism policy is to develop a socio-economic environment enabling the sector to sustainably prosper (Ritchie and Crouch 2003), while the diversity within the tourism industry presents opportunities for synergies with public health. To date, the potential for tourism and public health to cooperate in cultivating public wellbeing has not been assessed. This study aims to critically evaluate the potential for a strategic alliance between tourism, 
public health and wellbeing at the destination level, in order to improve place perceptions and present rebranding opportunities.

Through the lens of the eudaimonic approach to wellbeing, there lies an opportunity to promote sustainable, healthy lifestyles across the UK. The pairing of wellbeing (public health) and tourism as a strategic alliance presents a theoretical gap and area and thus, an area for research inquiry. Currently, the direct annual healthcare costs of physical inactivity in the UK are $£ 1.6$ billion, with an additional impact on the economy of $£ 8$ billion in indirect costs (which refers to the economic value of healthy lives lost to premature immortality). In the UK, nearly half the population fail to meet physical activity targets, where physical inactivity is responsible for approximately $17 \%$ of all deaths in the UK. It is estimated that interventions targeting one fifth of Britons that are currently inactive may achieve economic benefits valuing $£ 2.4$ billion (ISCA/Cebr 2015).

\section{Defining the term 'wellbeing'}

Eudaimonic theorising emerged originally as a challenge to subjective wellbeing with its focus oncontentment, feeling good and life satisfaction (Bryant and Veroff 1982; Andrews and Withey 1976). Eudaimonic wellbeing theory (EWB) denotes the quality of life a person derives from fulfilment of their goals to reach their greatest potential (Waterman 2008;Sheldon 2002). Eudaimonic wellbeing is proposed to have emerged to accompany and diverge from subjective wellbeing as a means of studying and understanding quality of life (Kashdan et al. 2008; Ryan et al. 2008). Moreover, there are some researchers that use EWB synonymously with positive psychological functioning (Seligman 1999). Eudaimonic theories of wellbeing affirm the significance of achieving a person's full potential through engagement in meaningful activities (Steger et al. 2008). Studies indicate that eudaimonic behaviours are more strongly related to wellbeing than hedonic behaviours (Steger et al. 2008). This paper therefore approaches wellbeing from the eudaimonic perspective as a means of promoting a tourism destination product that nurtures a greater quality and quantity of life.

\section{Methodological approach}

The findings presented within this paper are drawn from a wider study which evaluated the potential for synergies between wellbeing, public health and tourism at a coastal destination. This paper focuses on the most widely discussed strategies for intradepartmental synergies, in the context of place, or the coastal environment. The study was conducted between September and December 2013 in a town in the south of England, in a county with 142 kilometres of coastline.

A constructive grounded theory approach was used in the development of this study. A purposive sample of sixteen participants was recruited from public health and tourism departments in the local authority (8 from each team). The aim of the interviews was to understand the meanings participants associated with wellbeing and explore how wellbeing may be operationalised in collaborative public health and tourism planning agendas. 
Data collection and analysis was conducted simultaneously, where interviews were coded as soon as they were transcribed. All study data was coded using an organising scheme (coding paradigm) that focused on: the conditions, the circumstances and situations that form the structure of the studied phenomenon; actions/interactions, participants routine or strategic responses to issues, events or problems; and consequences; the outcomes of the studied actions and interactions. Finding ways of engaging with a healthy tourism "offer" emerged as the core category, the context of place category, explored in this paper, highlights the influence of place on the core category.

\section{Findings}

Four main themes emerged from interview data - understanding place through health and tourism roots, a healthy offer for locals and for tourists, reshaping the public space and using wellbeing to define the destination. Study evidence is evaluated within this section alongside key theoretical constructs drawn from the literature in order to explain the range of perceptions held about the town and the strategies identified to develop a wellbeing destination.

\section{Understanding place through health and tourism roots}

As noted by Nunn (1906), since the 1870s the town had gained itself a reputation of being a health resort. Walton (1981) suggests a connection between the Victorian growth of seaside resorts and the white collar demand for health-related recreation opportunities. Participants within the study recognised the historical connections of the town with health and wellbeing:

"There were a lot of pine trees, so it was seen as a very good place for people with breathing difficulties. So a lot of spas and hotels grew up to accommodate the people who were travelling to be down by the sea and have a break from the hectic life that was London, and that was the beginning of the tourism industry".

Other participants also identified the role of the pine trees and the associated benefits, with the town's tourism growth and development:

"The town grew up as a tourist place, but one of the main things was health....and that doctor who visited the pine trees".

The early development of seaside towns was due to the eighteenth century medical professionals advising their patients to visit seaside resorts for their health benefits (Gilbert 1939). The town's medical officer connected pine trees to being a wind screen for aseptic respiration, providing a health influence to the town's climate. From this perspective, visiting and bathing was not seen as a pleasure but, a medicinal bath. Gilbert (1939) argues that many places flourished as resorts as a result of them being selected by court doctors as places where royals may improve their health.

Historical research similarly reveals that the town had, since the 1870's gained itself a reputation of being a health resort (Nunn 1906). Historical research supports the 
connection between the Victorian growth of the seaside resorts and the white collar demand for health related recreation opportunities (Walton 1981). It is also put forward, however, that from an early stage, railways ran cheap trips to the south of England, opening up seaside travel to the masses (Gilbert 1939). Historical research suggests that the working-class seaside holiday diversified demands for leisure activities, attracting tourists who sought pleasures from the beach as well as the beer house (Walton 1974).

\section{Role of tourism}

Tourism was identified as being central to the town's identity. Participants from both public health and tourism teams recognise that it's "a huge part of the town", "a shop window to the world", and "one of the market leading seaside resorts in the country". Study evidence highlights the pivotal role of tourism in the town, suggesting its impact on council business, by virtue of the strength of the tourist economy. Participants from both public health and tourism teams acknowledge the impacts of the tourism industry:

"For a town our size, we punch a little above our weight because we have a long coastal strip that attracts people in".

"It's a town that doubles in size in the summer...how on earth does the infrastructure cope with that?"

Linked to the impacts of tourism, past literature contends that economic benefits of tourism can be eroded when tourists negatively impact daily patterns of life (Ryan et al 1998; Doxey 1975). Additionally, it is suggested that residents' perceptions of tourism impacts and their support, are linked to the destination's stage within the destination lifecycle (Gursoy et al. 2009). If the destination is in the stagnation phase of the tourism lifecycle, then there are more negative attitudes to both tourism and tourists (Butler 1989).

In the past, host perceptions of tourism have focused on the economic impacts (Walpole and Goodwin 2000; Li 1987). This is similar to some of the participants' views about the connections between the tourism industry and greater infrastructure and service developments. The exploration of social dimensions, a more recent research focus, predominantly employs the social exchange theory to investigate the topic (Gursoy and Rutherford 2004). The social exchange theory is guided by the principle that more people are likely to participate in a social exchange when they perceive that they will accrue benefits without any unacceptable costs (Allen et al. 1993). Participants revealed a wide range of perceptions held about the town ranging from it being one of the happiest places to it being full of out of control teenagers. During interviews, many participants mentioned their perceptions about the town in relation to levels of happiness:

"I think the town is one of the happiest places to live officially".

From another perspective, selected study evidence reveals some of the negative views that have been associated with the town: 
"You know people around the country may have perhaps a slightly negative view of what [the town] is... a bit sort of old fashioned, a bit like a Victorian lady in a crinoline skirt or some people may have a view that it's all about nightclubs and teenagers out of control, that kind of stuff".

Findings are consistent with current literature which confirms that the considerable expansion of the 'night-time' economy in British cities and towns (Roberts and Turner 2005; Hobbs et al. 2003), relaxed liquor licensing laws (Elvins and Hadfield 2003) on UK high streets targeting 18-24 year olds (Mintel 2004) have impacted the public space on the street at night (Roberts 2006). While local councils may be criticised for allowing such expansion, it could be argued that permissive attitudes were based on the desire to promote urban regeneration in ailing town centres (Roberts 2006).

Participants also identified some of the negative place perceptions held regarding areas of deprivation:

"Because some of the areas they are tackling around drug dependency and alcohol have quite a negative impact on how people view [area of deprivation] and might keep people away."

“You wouldn't get tourists in areas of deprivations...you might, if you make it a nicer place to be".

\section{Healthy offer for locals and tourists}

In an effort to reduce the negative perceptions held by the host community, participants recognised the important role of locals in shaping the destination offerings. Many participants acknowledged how the majority of seafront use is by local residents:

"Our guaranteed seafront users year round, it's the residents and even in the height of the summer...nearly $60 \%$ of our beaches is our residents, so if you get the offer right for the residents then the tourism offer sort of follows behind".

"Because it's a destination, it's by the sea, it is a recreational destination, they have a lot of wellbeing activities...if you look at the usage on the beach, it tends to be lots of local people that do it, it's not just people coming in".

Recreation and tourism have been identified as agents of change in landscape development (Palang et al 2005; van der Vaart 2003), further suggesting that resident place relations and their needs are equally important considerations to those of the tourists (Klanika et al. 2006). Thus, one of the strategies identified to improve the local perceptions of tourism, is to involve residents in the tourism planning process to determine the overlapping demands and expectations of locals and tourists.

\section{Reshaping the public space}

Several participants recognised opportunities to reshape the public space and potentially rebrand the destination to promote a healthier tourism "offer". 
"If you are thinking about defining your future tourism offer, what's different about the town, how are they going to shape that? How are they going to sharpen it? They could really start to differentiate that tourism offer and link it more strongly to wellbeing".

The concept of 'arts-led' regeneration has been explored in places like Glasgow, Barcelona and Bilbao as a means to utilising cultural initiatives as catalysts for urban regeneration (García 2004). Further, it is recommended that if a cultural project is going to lead regeneration efforts it requires strong destination brand (Tibbot 2002). Participants with the public health team in particular, recognise the potential of artsled initiatives within one of the town's areas of deprivation:

"That's where we are going to be trying to raise the level of wellbeing in that area, which could raise the level of the whole area up".

"People will hopefully view [area of town] as the type of place to come if you are a bit arty and creative and go along and see all this interesting art.... and start to turn it into a quirky artsy kind of place... it creates a unique feel to it".

\section{Wellbeing defining the destination}

In exploring areas for departmental synergies and rebranding, participants identified their perspectives about the town as a wellbeing destination:

"Its creation was really based on wellbeing because the first house that was built in town was so people could get out of smoky London, and come down and enjoy the fresh healthy sea air. So it started off being a wellbeing destination and I think there is a need to have an investment, to make wellbeing be more of a wellbeing product" "For the destination, we've always said that it's about the prosperity, about a prosperous healthy destination, that isn't just about economic health, but wider considerations, like is it contributing to people's happiness and wellbeing?".

Reflecting on the role of the coastal environment, participants connected experiences in the natural environment with the promotion of happiness and wellbeing. Similarly, Kyle and colleagues (2004), contend that people search for environments to recuperate from stressful aspects of their lives and that people have a greater sense of attachment to places which provide a means to escaping from daily pressures. Additionally, Ulrich (1983) suggests that nature may permit psychophysiological stress recovery through responses to natural environment attributes which include spatial openness and water features.

\section{Conclusion}

Study evidence highlighted how the historical roots of the town's creation have a bearing on current perceptions, planning challenges and strategies, as the area was originally popularised for both its seaside health benefits and also for its beer houses. Currently, while there is an interest in promoting a healthier or wellbeing tourism destination, there remains a thriving night-time economy which features 
excessive alcohol consumption. Similarly, study evidence highlights the diversity of perceptions that are held about the area which range from the "happiest place in the UK" through to one that is "all about nightclubs and teenagers out of control". Furthermore, the study findings acknowledge that areas of deprivation and the associated negative health behaviours have a negative impact on place perceptions and the local tourism industry. Thus, one of the area of potential synergy between public health and tourism may be around interventions to curb alcohol consumption and regenerate areas. Participants from local public health and tourism teams underscored the significant role of the natural seaside environment, in promoting wellbeing. In understanding the host community expectations of tourism, locals could be engaged in the tourism planning process, further assessing the intersections of local and tourist expectations. Furthermore, this strategy could bridge collaboration between public health and tourism local departments. The health benefits of experiencing the natural environment provides an avenue for co-located wellbeing interventions that benefit residents and tourists alike. In building a healthier tourism strategy, both public health and tourism teams may be interested in the reduction of binge drinking, regeneration and the promotion of alternative forms of tourism product. For example, arts-led regeneration efforts may address the public health agenda issues, while presenting a destination branding opportunity through the reshaping of place. The engagement with a healthy tourism "offer" at the destination level, provides an opportunity to alter place perceptions through intradepartmental strategies, which promote wellbeing as a destination.

\section{References}

Allen, L., Hafer, H., Long, R., and Perdue, R. (1993). Rural residents' attitudes toward recreation and tourism development. Journal of travel research, 31(4), 27-33. Andrews, F.M. and Withey, S.B. (1976). Social indicators of well-being: Americans' perceptions of life quality. New York:

Plenum. Bryant, F.B., and Veroff, J., (1982). The structure of psychological wellbeing: a sociohistorical analysis', Journal of personality and social psychology, 43, 653-673.

Butler, R. (1989). "Alternative Tourism: Pious Hope or Trojan Horse?" World Leisure and Recreation, 31 (4): 9-17.

Daniel, T.C., Muhar, A., Amberger, A., Aznar, O., Boyd, J.W., Chan, K.M.A, Costanza, R., Elmqvist, T., Flint, C.G., Gobster, P.H. et al. (2012). Contributions of cultural services to the ecosystem services agenda. PNAS, 109(23), 89128919.

Doxey, G.V., (1975). A causation theory of visitor-resident irritants, methodology and research inferences. The impact of tourism. Sixth annual conference proceedings of the travel and tourism research association, San Diego, 195-198.

Elvins, NS and Hadfield, M.P., (2003). West end stress area, night-time economy profiling: A demonstration project, Department of Sociology and Social Policy, University of Durham, Durham.

Fayers, P. M. and Machin, D. (2007) Scores and measurements: validity, reliability, sensitivity, in quality of life: the assessment, analysis and interpretation of patientreported outcomes, Second edition, John Wiley \& Sons, Ltd, Chichester, UK. 
Garcia, B. (2004) Cultural policy and urban regeneration in western european cities:lessons from experience, prospects for the future, Local Economy, 19(4), 312326.

Gilbert, E.W., (1939). The growth of Inland and seaside health resorts in England. Scottish geographical magazine, 55(1), 16-35.

Gursoy, D., Chi, C. G., \& Dyer, P. (2009). An examination of locals' attitudes. Annals of Tourism Research, 36, 723 - 726.

Gursoy, D., and Rutherford, D.G., (2004). Host attitudes toward tourism and improved structural model. Annals of tourism research, 31(3), 495-516.

Hair, J., Black W., Babin B. \& Anderson R. (2010). Multivariate data analysis. 7th edition. Upper Saddle River, New Jersey: Prentice Hall.

Hobbs, D., Hadfield, P., Lister, S. and Winlow, S. (2003). Bouncers: Violence and Governance in the Night-time Economy, Oxford: Oxford University Press.

ISCA/ Cebr. (2015). The economic cost of physical inactivity in Europe. Centre for Economics and Business Research.

Kasdan, T.B., Biswas-Diener, R., and King, L.A., (2008). Reconsidering happiness: the costs of distinguishing between hedonics and eudaimonia. The journal of positive psychology, 3, 219-233.

Klanicka, S., Buchecker, M., Hunziker, M., and Muller-Boker, U., (2006). Locals' and tourists' sense of place: a case study of a Swiss alpine village, Mountain research and development, 26 (1), 55-63.

Kyle, G.T., Mowen, A.J., and Tarrant, M., (2004). Linking place preferences with place meaning: an examination of the relationship between place motivation and place attachment. Journal of environmental psychology, 24, 439-454.

$\mathrm{Li}, \mathrm{H}$. (1987). PR China's tourism industry today and its future development. Tourism management, Vol. 8 No. 2, pp. 90-1.

McCabe, S., Joldersma, T., and Li, C. (2010). Understanding the benefits of social tourism: linking participation to subjective wellbeing and quality of life. International journal of tourism research, 12(6), 761-773.

Mintel, (2004). Health and wellness tourism: global travel and tourism analyst. London: Mintel International Group.

Munthe, C. (2008). The goals of public health: an integrated multidimensional model, Public health ethics, 1(1), 39-52.

Nunn, P.W.G., (1906). Sanitary administration in a health resort. The journal of the Royal Society for the promotion of health, 27, 290-304.

Palang, H., Helmfrld, S., Antrop, M., Alumae, H., (2005). Rural landscapes: past processes and future strategies. Landscape and urban planning, 70: 3-8.

Ritchie, J.R.B., \& Crouch, G.I. (2003). The competitive destination: a sustainable tourism perspective. Oxon, UK: CABI Publishing.

Roberts, B., (2005). The end of oil. London: Bloomsbury.

Roberts, M. (2006) From 'creative city' to 'no-go areas'. The expansion of the nighttime economy in British town and city centres. Cities, 23 (5): 331-338.

Ryan, R.M., Huta, V. and Deci, E.L. (2008). Living well: a self-determination theory perspective on eudaimonia. Journal of happiness studies, 9: 139-170.

Seligman, M. (1999). Positive social science [president's column]. APA Monitor, 2. Sheldon, K.M., (2002). The self-concordance model of healthy goal striving: when personal goals correctly represent the person. In: Deci, E.L., and Ryan, R.M. (eds.) Handbook of self-determination research. University of Rochester Press:

Rochester. 
Skevington, S.M., Lotfy, M., and O'Connell, K.A., (2004). The World Health Organisation's WHOQOL-BREF quality of life assessment: psychometric properties and results of the international field trial - A report from the WHOQOL Group. Quality of life research, 13, 299-310.

Steger, M.F., Kashdan, T.B., and Oishi, S., (2008). Being good by doing good: daily eudaimonic activity and well-being. Journal of research in personality, 42, 22-42. Tibbot, R. (2002) Culture club. Can culture lead urban regeneration? Locum Destination Review, No.9, Autumn, pp. 71-73.

Ulrich, R.S., (1983). Aesthetic and affective response to natural environment. Behavior and the natural environment. New York: Plenam PressAltman, 85-125. Van der Vaart, J.H.P. (2003). Towards a new rural landscape: consequences of nonagricultural re-use of redundant far buildings in Friesland. Landscape and urban planning, 701 143-152.

Walpole, M., and Goodwin, H., (2000). Local economic impacts of dragon tourism in Indonesia. Annals of tourism research, 27, 559-576.

Walton, J.K., (1981). The demand for working-class seaside holidays in Victorian England. The economic history review, 34(2), 249-265.

Waterman, A.S., (2008). Reconsidering happiness: a eudaimonist's perspective. Journal of positive psychology, 3, 234-252.

Wise, N., and Peric, M., (2016). Sports tourism, regeneration and social impacts: new opportunities and directions for research, the case of Medulin, Croatia. In: Bellinin, N. and Pasquinelli, C., (Eds). Tourism in the city, Springer:Switzerland 311320. 